\title{
Effect of Circuit Training on Resting Blood Pressure: An Experimental Study in Hypertensive Older Women
}

\author{
Diogo Cardozo ${ }^{1 *}$, Denise Destro ${ }^{2}$ and Ana Paula Sena Vasconcelos ${ }^{1}$ \\ ${ }^{1}$ Faculdade Metodista Granbery - FAMIDADE, Juiz de Fora, Brazil \\ ${ }_{2}^{2}$ Secretaria de Educação de Juiz de Fora, MG, Brazil
}

Submission: July 29, 2020; Published: August 18, 2020

*Corresponding author: Diogo Cardozo, Faculdade Metodista Granbery, Rua Batista de Oliveira 1.145, Granbery, Juiz de Fora, MG, Brazil

\begin{abstract}
Background: Hypertension is considered a primary risk factor for heart disease in the elderly. However, strength training can help control
\end{abstract} blood pressure levels.

Methods: Twenty elderly hypertensive women $(73.6 \pm 8.1$ years, $61.6 \pm 11.8 \mathrm{~kg}, 153.3 \pm 5.8 \mathrm{~cm})$ were recruited to participate in this study. All of them underwent resting blood pressure, anthropometric and muscle strength measurements. The training protocol was performed in a circuit (CT), with three sets of 8 to 10 repetitions with 30 -second intervals between sets and 1 minute between sequences. Training was performed twice a week for twelve weeks. The exercises were performed following this sequence: leg press, bench press, knee extension, lat pulldown, plantar flexion, and triceps extension.

Results: After 12 weeks of CT, significant improvements in body composition ( $p \leq 0.05)$, increased levels of muscle strength $(p=0.001)$ and reduced systolic blood pressure $(\mathrm{p}=0.001)$ were observed. There were no differences in body weight, $\mathrm{BMI}$, and diastolic blood pressure $(\mathrm{p}=$ $\geq 0.05$ ). women

Conclusion: The CT protocol is efficient for improving physical conditioning and reducing systolic blood pressure in hypertensive older

Keywords: Hypertension; Strength training; Elderly; Geriatrics

\section{Introduction}

Human aging produces several morphological, functional, and biochemical changes exposing the elderly to the risk of acquiring chronic degenerative diseases, such as diabetes, obesity, hypertension, osteoporosis, among others [1,2]. Considering chronic degenerative diseases, hypertension is one of the most important factors for heart disease and other disorders affecting the circulatory system [3]. Previous data have shown high prevalence among the adults, and even higher among the elderly $[4,5,6]$. In addition, older people also experience loss of muscle strength, which can adversely affect the performance of activities of daily living and quality of life in this population. For this reason, strength training (ST) is indicated for older people, as it contributes to lower blood pressure (BP) at rest, to increase muscle strength, bone mineral density, to improve functional capacity, and other benefits [1,2,7-9].
Recognized health organizations such as the American College of Sports Medicine and the American Heart Association recommend ST as a non-pharmacological support to control blood pressure $[1,4]$. However, most studies investigating hypertensive elderly population have focused on training intensity [10]. Therefore, considering that the ST can be manipulated by the combination of different training methods and systems, it is worth supporting further research that investigate other training possibilities. For this reason, the aim of the present study was to verify the effect of 12 weeks of circuit training on resting blood pressure in hypertensive older women.

\section{Materials and Methods}

\section{Sample}

Twenty older women were selected from an active aging program in the city of Juiz de Fora, MG, Brazil. This program is 
offered to the community aiming to promote health and education for this population through a range of activities (physical, cognitive, and social interaction). Inclusion criteria adopted for participation in this study were: a) elderly women (60 years old or over), b) controlled arterial hypertension, c) absence of significant joint/ muscle impairment that could affect the evaluation and physical training routines, d) cognitive capacity to understand physical training routines and e) cardiologist's approval to participate in physical training sessions. The physical characteristics of the sample are explained in table 1. This study was approved by Institutional Review Board of Faculty of Medical and Health Sciences of Juiz de Fora (Brazil) number 847,611. All volunteers were informed of the objectives and procedures of this study. Once the terms were agreed, the volunteers were evaluated as reported below:

Table 1: Values expressed as mean and standard deviation in pre- and post-training.

\begin{tabular}{|c|c|c|c|}
\hline Variables & Pre-training & Post-training & Difference post-pre \\
\hline Age (years) & $73.6 \pm 8.1$ & - & - \\
\hline Height $(\mathrm{cm})$ & $153.3 \pm 5.8$ & - & - \\
\hline Weight (kg) & $61.6 \pm 11.8$ & $61.9 \pm 11.4$ & 0.3 \\
\hline BMI & $26.2 \pm 4.8$ & $26.3 \pm 4.6$ & 0.1 \\
\hline Lean body mass $(\mathrm{kg})$ & $35.6 \pm 4.3$ & $36.8 \pm 4.2^{*}$ & 1.2 \\
\hline Fat mass (kg) & $25.9 \pm 7.5$ & $25.1 \pm 7.6^{*}$ & -0.8 \\
\hline$\%$ Body fat & $41.4 \pm 4.6$ & $39.8 \pm 5.2^{*}$ & -1.6 \\
\hline $\mathrm{SBP}(\mathrm{mmHg})^{\mathrm{a}}$ & $140.4 \pm 9.6$ & $130.3 \pm 9.8^{*}$ & -10.1 \\
\hline $\mathrm{DBP}(\mathrm{mmHg})^{\mathrm{b}}$ & $76.5 \pm 6.5$ & $73.9 \pm 6.8$ & -2.6 \\
\hline Muscle strength $^{c}(\mathrm{~kg})$ & $24.9 \pm 6.5$ & $39.0 \pm 8.0^{*}$ & 14.1 \\
\hline
\end{tabular}

$a=$ systolic blood pressure; $b=$ diastolic blood pressure; $c=$ lower limb strength; *Indicates statistical difference in relation to pre-training ( $p \leq 0.05)$.

\section{Resting blood pressure}

Resting blood pressure measurements were taken after a 10-minute rest period, with the sphygmomanometer positioned on the right arm, sitting position, supported back and uncrossed legs. Two readings were performed with an interval of 5 minutes between readings. Depending on the magnitude of the difference between readings, if it were greater than $5 \mathrm{mmHg}$ from first to second reading, a third reading would be performed. The lowest value between measurements was considered as resting BP. All procedures are in accordance with the American Heart Association [11].

\section{Anthropometric measurements:}

Body weight was measured with a calibrated scale and height was measured using a stadiometer. For body composition measurements, the skinfold protocol by Durnin and Womersley was used [12].

\section{Muscle strength test:}

After a two-week period of familiarization, the volunteers were submitted to a test of 10 maximum repetitions (RM) in the leg press exercise. The test and retest were performed on two non-consecutive days (48h interval) to determine the reliability of the measurements. All volunteers had up to five attempts with a 5-minute interval between attempts to determine the 10RM load. The heaviest load between two days was considered 10RM load [8]. After twelve weeks of circuit training, measurements of rest blood pressure, anthropometric measurements and lower limb muscle strength were repeated.

\section{Training Protocol}

After first procedures, the volunteers were submitted to the circuit training with three sets with a 30 second interval between exercises and 1 minute to restart the sequence. The number of repetitions was between 8-10 and the training loads were adjusted using the Omni-Res perception scale [8,13]. The training frequency was twice a week for 12 weeks. The exercises were performed as following: leg press, bench press, knee extension, lat pulldown, plantar flexion, and triceps extension.

\section{Statistical Analysis}

Initially the Shapiro-Wilk normality test was applied with all variables showing normal distribution. Subsequently, the paired t-test is used to analyze the differences in measurements considering pre- and post-training periods. Data are presented as a mean and standard deviation and a significance level of $\mathrm{p} \leq 0.05$ was considered for all comparisons. All data were analyzed using IBM SPSS version 20.0.

\section{Results}

Table 1 shows the comparisons between the periods of preand post-training. After 12 weeks of circuit training, significant differences were observed for Lean body mass ( $p=0.001)$, fat mass $(p=0.004), \%$ body fat $(p=0.001)$, systolic blood pressure 
(SBP) ( $p=0.001)$ and in muscle strength of the lower limbs muscle $(p=0.001)$. However, there were no differences for variables such as weight ( $p=0.069)$, BMI ( $p=0.771)$ and diastolic blood pressure (DBP) $(\mathrm{p}=0.121)$.

\section{Discussion}

The results of this study demonstrated that 12 weeks of circuit training revealed significant increases in muscle strength and mass, decreases in fat mass, fat percentage and SBP in hypertensive older women. Concerning blood pressure, the results reveal great importance clinical, as the training protocol promoted a reduction of $10.1 \mathrm{mmHg}$ in SBP. The magnitude of SBP reduction after the training period was higher than the values reported by some metaanalyses that showed reductions between 3.5 and $8.2 \mathrm{mmHg}$ in SBP $[10,14]$. Previous evidence suggested that a reduction of only $3 \mathrm{mmHg}$ in blood pressure may reduce the risk of stroke, coronary artery disease and cardiovascular mortality [4].

There were no statistical differences about DBP in this study. However, other research has demonstrated significant reductions in DBP after a period of ST. These differences can happen due to different ST protocols and probably to the initial values in the DBP $[15,16]$. In the present study, the volunteers showed controlled values for this physiological variable. Besides cardiovascular complications, human aging results in a loss of muscle mass and strength negatively affecting autonomy. Therefore, the loss of muscle mass and strength in the elderly makes it more difficult for them to perform activities of daily living. This physical deconditioning can expose older people to other diseases, such as diabetes, obesity, osteoporosis, among others. On the other hand, when they are submitted to a health-oriented ST program, they can reverse/minimize negative effects of aging $[1,2,9,17]$.

Our results demonstrated that the circuit training protocol is efficient to increase muscle mass, strength levels and reduce the percentage of fat in this population. These results corroborate with other studies developed in other age groups, showing that even at older ages the capacity of increasing strength and muscle mass is preserved [18]. This study has some methodological limitations, such as the absence of a control group and more sophisticated measures to investigate muscle mass. However, the results here highlight the importance of circuit training prescription as a lowcost option aiming to enhance physical conditioning and control blood pressure at rest.

\section{Conclusion}

In conclusion, the circuit training protocol proves effective not only in improving physical fitness but also reducing blood pressure at rest in hypertensive older women.

\section{References}

1. Williams MA, Haskell WL, Ades PA, Ezra A Amsterdam, Vera Bittner, et al (2007) Resistance exercise in individuals with and without cardiovascular disease: 2007 update: a scientific statement from the American Heart Association Council on Clinical Cardiology and Council on
Nutrition, Physical Activity, and Metabolism. Circulation 116(5): 572584 .

2. American College of Sports Medicine (2009) Position stand on exercise and physical activity for older adults. Med Sci Sports Exerc 41(7): 1510-1530.

3. Chobanian AV, Bakris G, black HR et al (2003) Seventh report of the joint national committee on prevention, detection, evaluation, and treatment of high blood pressure. Hypertension 42:1206-1252.

4. Pescatello LS, Franklin BA, Fagard R, William B Farquhar, George A Kelley, et al (2004) Exercise and hypertension. Med Sci Sports Exerc 36: 533-553.

5. Aronow WS, Fleg JL, Pepine CJ, Nancy T Artinian, George Bakris, et al (2011) Expert consensus document on hypertension in the elderly: a report of the American college of cardiology foundation task force on clinical expert consensus documents. Circulation 123:2434-2506.

6. Picon RV, Fuchs FD, Moreira LB, Riegel G, Fuchs SC (2012) Trends in prevalence of hypertension in Brazil: a systematic review with meta-analysis. PloS one 7(10): e48255.

7. Vasconcelos APSL, Cardozo DC, Lucchetti ALG, Lucchetti G (2016) Comparison of the effect of different modalities of physical exercise on functionality and anthropometric measurements in community-dwelling older women. J Bodyw Mov Ther 20(4): 851-856.

8. Cardozo D, de Salles BF, Mannarino P, Ana Paula Sena Vasconcelos, Humberto Miranda, et al (2019) The Effect of Exercise Order in Circuit Training on Muscular Strength and Functional Fitness in Older Women. Int J Exerc Sci 12(4): 657-665.

9. Fragala MS, Cadore EL, Dorgo S, Mikel Izquierdo, William J Kraemer, et al (2019) Resistance training for older adults: position statement from the National strength and conditioning association. J Strength Cond Res 33(8): 2019-2052.

10. De Sousa EC, Abrahin O, Ferreira ALL, Rodrigues RP, Alves EAC, et al. (2017) Resistance training alone reduces systolic and diastolic blood pressure in prehypertensive and hypertensive individuals: meta-analysis. Hypertens Res 40(11): 927-931.

11. Pickering TG, Hall JE, Appel LJ, Bonita E Falkner, John Graves, et al. (2005) Recommendations for blood pressure measurement in humans and experimental animals: part 1: blood pressure measurement in humans: a statement for professionals from the Subcommittee of Professional and Public Education of the American Heart Association Council on High Blood Pressure Research. Hypertension 45:142-161.

12. Durnin JVGA, Womersley JVGA (1974) Body fat assessed from total body density and its estimation from skinfold thickness: measurements on 481 men and women aged from 16 to 72 years. Br J Nutri 32(1): 77-97.

13. Gearhart RF, Lagally KM, Riechman SE, Andrews RD, Robertson RJ (2011) Safety of using the adult omni resistance exercise scale to determine 1-rm in older men and women. Percept and Mot skills 113(2): 671-676.

14. Cornelissen VA, Fagard RH (2005) Effect of resistance training on resting blood pressure: a meta-analysis of randomized controlled trials. J Hypertens 23(2): 251-259.

15. Moraes MR, Bacurau RF, Casarini DE, Zaira P Jara, Fernanda A Ronchi, et al (2012) Chronic conventional resistance exercise reduces blood pressure in stage 1 hypertensive men. J Strength Cond Res 26(4): 11221129.

16. Moraes MR, Bacurau RFP, Simões HG, C S G Campbell, M A Pudo, et al (2012) Effect of 12 weeks of resistance exercise on post-exercise hypotension in stage 1 hypertensive individuals. J Human hypertens 26(9): 533-539. 
17. Lopez P, Pinto RS, Radaelli R, Anderson Rech, Rafael Grazioli, et al (2018) Benefits of resistance training in physically frail elderly: a systematic review. Aging Clin Exp Res 30(8): 889-899.
18. Fiatarone MA, Marks EC, Ryan ND, Meredith CN, Lipsitz LA, et al. (1990) High-intensity strength training in nonagenarians: effects on skeletal muscle. Jama 263(22): 3029-3034.

\section{Your next submission with Juniper Publishers will reach you the below assets}

- Quality Editorial service

- Swift Peer Review

- Reprints availability

- E-prints Service

- Manuscript Podcast for convenient understanding

- Global attainment for your research

- Manuscript accessibility in different formats

( Pdf, E-pub, Full Text, Audio)

- Unceasing customer service

Track the below URL for one-step submission https://juniperpublishers.com/online-submission.php 